\title{
Maternal near miss among women admitted in major private hospitals in eastern Ethiopia: a retrospective study
}

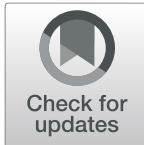

Shegaw Geze Tenaw ${ }^{1}$, Nega Assefa ${ }^{2}$, Teshale Mulatu ${ }^{2}$ and Abera Kenay Tura ${ }^{2,3^{*}}$

\begin{abstract}
Background: Since maternal mortality is a rare event, maternal near miss has been used as a proxy indicator for measuring maternal health. Maternal near miss (MNM) refers to a woman who nearly died but survived of complications during pregnancy, childbirth or within 42 days of termination of pregnancy. Although study of MNM in Ethiopia is becoming common, it is limited to public facilities leaving private facilities aside. The objective of this study was to assess MNM among women admitted in major private hospitals in eastern Ethiopia.

Methods: An institution based retrospective study was conducted from March 05 to 31, 2020 in two major private hospitals in Harar and Dire Dawa, eastern Ethiopia. The records of all women who were admitted during pregnancy, delivery or within 42 days of termination of pregnancy was reviewed for the presence of MNM criteria as per the sub-Saharan African MNM criteria. Descriptive analysis was done by computing proportion, ratio and means. Factors associated with MNM were assessed using binary logistic regression with adjusted odds ratio (aOR) along with its $95 \%$ confidence interval (Cl).

Results: Of 1214 pregnant or postpartum women receiving care between January 09, 2019 and February 08, 2020, 111 women developed life-threatening conditions: 108 MNM and 3 maternal deaths. In the same period, 1173 live births were registered, resulting in an MNM ratio of 92.1 per 1000 live births. Anemia in the index pregnancy (aOR: 5.03; 95\%Cl: 3.12-8.13), having chronic hypertension (aOR: 3.13; 95\% Cl: 1.57-6.26), no antenatal care (aOR: 3.04; 95\% Cl: 1.58-5.83), being $\geq 35$ years old (aOR: 2.29; 95\%Cl: 1.22-4.29), and previous cesarean section (aOR: 4.48; 95\% Cl: 2.67-7.53) were significantly associated with MNM.

Conclusions: Close to a tenth of women admitted to major private hospitals in eastern Ethiopia developed MNM. Women with anemia, history of cesarean section, and old age should be prioritized for preventing and managing MNM. Strengthening antenatal care and early screening of chronic conditions including hypertension is essential for preventing MNM.
\end{abstract}

Keywords: Maternal near miss, Private hospitals, Ethiopia, Maternal audit

\footnotetext{
* Correspondence: daberaf@gmail.com

${ }^{2}$ School of nursing and midwifery, College of Health and Medical Sciences, Haramaya University, P.O.B. 235, Harar, Ethiopia

${ }^{3}$ Department of obstetrics and gynecology, University Medical Centre Groningen, University of Groningen, Groningen, the Netherlands

Full list of author information is available at the end of the article
} 


\section{Background}

At the end of the Millennium Development Goals, ending maternal mortality remained the unfinished agenda and improving maternal health, well-being and survival remains central goal and investment priority of the Sustainable Development Goals [1]. Although maternal mortality decreased by $38 \%$ since 2000 in sub-Saharan Africa, 66\% of the 295,000 maternal deaths in 2017 occurred in the region [2].

Globally, maternal mortality is used to monitor maternal health, quality of reproductive health care, and progress towards international goals [2, 3]. However, maternal death is a rare event in absolute terms at individual health facilities, including in high burden countries limiting their significance in generating essential lessons for improving maternal health [4]. In addition, maternal mortality figures, by definition, shows negative endpoint irrespective of interventions provided. These led to the emergence of the concept of maternal near miss (MNM), for evaluating the quality of maternal health care as a proxy indicator for measuring maternal health $[4,5]$.

According to the World Health Organization (WHO), MNM is defined as "a woman who nearly died but survived a complication that occurred during pregnancy, childbirth or within 42 days of termination of pregnancy" [5]. MNM could serve as a proxy indicator for maternal death and allows for more rapid assessment of maternal health care. It also serves as a surrogate to gain a better understanding of a set of conditions and preventable factors which contribute to maternal death [6]. Even though maternal mortality is considered to be one of the main indicators of maternal health, it shows only a small fraction of the maternal ill-health continuum and understanding the true burden of maternal ill-health requires studying near miss in addition to maternal deaths.

Depending on the definitions applied, for every woman in Ethiopia who dies from pregnancy related causes, 12 to 21 others experience near miss [7, 8]. In addition, MNM studies in low resource settings are subjected to under reporting because of low applicability of the MNM identification criteria [9-11]. So, a proposed subSaharan African MNM tool was developed through an international Delphi study [12]. In three rounds of Delphi among experts who used the existing WHO MNM tool in sub-Saharan Africa, the existing WHO MNM criteria were rated based on their feasibility with regard to diagnostic capabilities, presence of infrastructure and ability to diagnose the conditions. As such, the sub-Saharan African MNM tool containing 27 MNM indicators was developed. Details of the sub-Saharan African MNM tool and the Delphi study has been described elsewhere [12]. The applicability of the sub-
Saharan African MNM tool has been tested in Ethiopia and Namibia [8, 13].

Although studying of MNM in Ethiopia is becoming common since the first study in 2012, almost all the studies are limited to public health institutions [8, 1417]. Given the existence of variation in demographic, obstetrics and medical characteristics of women in public and private hospitals, and private facilities contributing significantly to care of women in pregnancy and childbirth [18, 19], existing studies failed to include the perspectives of private facilities and therefore our understanding of MNM is incomplete. Although a recent secondary analysis of the 2016 Ethiopian Emergency Obstetric and Newborn care estimated MNM, including in private facilities, the study failed to clearly indicate the burden separately for private facilities [20]. The objective of this study was to assess prevalence of MNM and associated factors among women admitted in major private hospitals in Harar and Dire Dawa Cities, eastern Ethiopia.

\section{Methods \\ Study settings}

The study was conducted in the obstetrics and gynecology units of two major private hospitals in Harar and Dire Dawa towns, eastern Ethiopia: Harar General Hospital and Bilal General Hospital. Harar General Hospital is a 33 bedded (five ICU) hospital serving for both referred and self-referred women, especially for a better off woman. During the study period, the unit was run by five consultants and six midwives. An estimated 900 deliveries occur per annum [21]. Bilal Hospital is a general 12 bedded (four ICU) hospital in Dire Dawa run by one consultant and seven midwives [22]. Both hospitals have one major operation theatre shared for all types of surgery. Unlike the public facilities, where all maternity services are free, majority of the women in these hospitals are from better off population and urban residents paying for all hospital services. The study was conducted from March 5 to 31, 2020.

\section{Study design and population}

Institution based cross sectional study was conducted among women admitted in the two hospitals during pregnancy, childbirth or within 42 days of termination of pregnancy during the period of January 9, 2019 to January 08, 2020 and fulfilled the validated sub-Saharan African MNM tool [8, 12, 13]. The sub-Saharan African MNM criteria contains 27 indicators (including 19 from WHO MNM tool) grouped in to clinical, laboratory and management-based approaches. The tool has already been tested in two studies from Ethiopia [8] and Namibia [13] and has been found to be effective for MNM studies in low resource settings. Incomplete 
medical records with missing of important variables were excluded. The minimum sample size was calculated using the WHO recommendation for calculating prevalence of severe maternal outcomes divided by the number of women giving birth within a given time period [23]. Considering the existing maternal mortality ratio and the annual number of deliveries, a total of 1000 live births were sufficient to identify 100 women with severe maternal outcomes. But considering the overall low deliveries in private facilities, we included all women who were admitted during the study period.

\section{Data collection}

Data were collected through review of all medical records using a standard checklist prepared for this purpose. Trained research assistants collected data on socio-demographic conditions of the woman, obstetrics history, pre-existing medical conditions, MNM events, underlying complications, and treatment received. Identification of MNM events was a two-step process. First, all medical records of women were screened for presence of any potentially life-threatening conditions (severe postpartum hemorrhage, severe pre-eclampsia, eclampsia, uterine rupture, severe complication of abortion and sepsis/ severe systemic infection), received critical interventions (use of blood products and laparotomy other than cesarean section) or admitted to the intensive care unit [5]. Then, women who developed lifethreatening complications consisting MNM and maternal deaths according to the sub-Saharan Africa MNM criteria were identified. Details of the sub-Saharan Africa MNM criteria, and its development and validation are described elsewhere [8, 12]. Information regarding whether the near miss was present before arrival or developed during hospitalization was collected to determine quality of care or delays in reaching facilities. Data on total number of deliveries and live births occurring during the study period for each hospital was extracted from the monthly hospital reports. The dependent variable was MNM defined as presence of any of the subSaharan Africa MNM criteria [8]. Independent variables included demographic characteristics (residence, age), obstetrics history (parity, history of cesarean section, history of abortion, history of stillbirth, and ANC utilization), and pre-existing medical conditions (chronic hypertension, anemia).

\section{Data processing and analysis}

Data were coded; double entered and cleaned using EpiData 3.1 and exported to SPSS 20 for analysis. Descriptive statistics of study participants and MNM indicators were analyzed. MNM ratio, severe maternal outcome ratio, mortality index (proportion of women who died from all sustained severe maternal outcomes,
$\left.\mathrm{MD} / \mathrm{MNM}+\mathrm{MD}^{*} 100\right)$ and MNM to mortality ratios were calculated [5]. In addition, hospital access indicators, such as the number of women with an MNM condition before arrival at the hospital, and number of women with near-miss who developed conditions in the hospital were also calculated. Continuous variables like age and parity were recorded to discrete: age $(<20,20-$ 34 , and $\geq 35$ ), parity (nullipara, $1-2$, and $\geq 3$ ). Bivariate logistic regression analysis was performed to see the association between each independent variable and MNM. Independent variables with -value of $\leq 0.25$ were selected for multiple logistic regression after checking for multi-collinearity using the Variance Inflated Factor (VIF) and standard error. Association was described using adjusted odds ratio along with $95 \% \mathrm{CI}$ and $p$-value $<0.05$ was considered as statistically significant.

\section{Results}

Of total 1287 admissions during pregnancy, childbirth, and within 42 days of termination of pregnancy, 1214 cases were included, after excluding 73 files which were incomplete or not accessible. During the same period, 1265 deliveries resulting in 1173 live births were registered in both hospitals. From these, 213 women were classified as having one or more of the potentially lifethreatening conditions, and 111 developed lifethreatening complications: $108 \mathrm{MNM}$ and 3 maternal deaths (Fig. 1). This resulted in an MNM ratio of 92.1 per 1000 live births, 94.3 and 87.2 for Harar General Hospital and Bilal Hospital, respectively. One maternal death occurred in Harar General Hospital and the other two were in Bilal Hospital, corresponding with an overall institutional maternal mortality ratio of 256 per 100,000 live births.

\section{Characteristics of participants}

The mean age of the participants was $26.4( \pm 5.2)$ years, ranging from 17 to 45 years. Majority of the study participants were from urban (66.9\%), admitted on working days (71\%), self-referred (97.3\%), received at least one ANC (92.5\%) and had no history of abortion (79.9\%) (Table 1).

\section{MNM indicators}

As indicated in Table 2, the MNM ratio was 92.1 per 1000 live births and for every maternal death, there were $36 \mathrm{MNM}$ cases. MNM ratio according to the WHO criteria was 40.9 per 1000 livebirths with lower MNM to mortality ratio (16:1) and higher morality index (5.9). The mortality index was $2.7 \%$, and was highest among cases referred from other facilities (4.5\%) compared to self-referrals (2.2\%). High proportions $(90 ; 81.1 \%)$ of MNM were already present on arrival or developed within $12 \mathrm{~h}$ of admission (Table 2). 


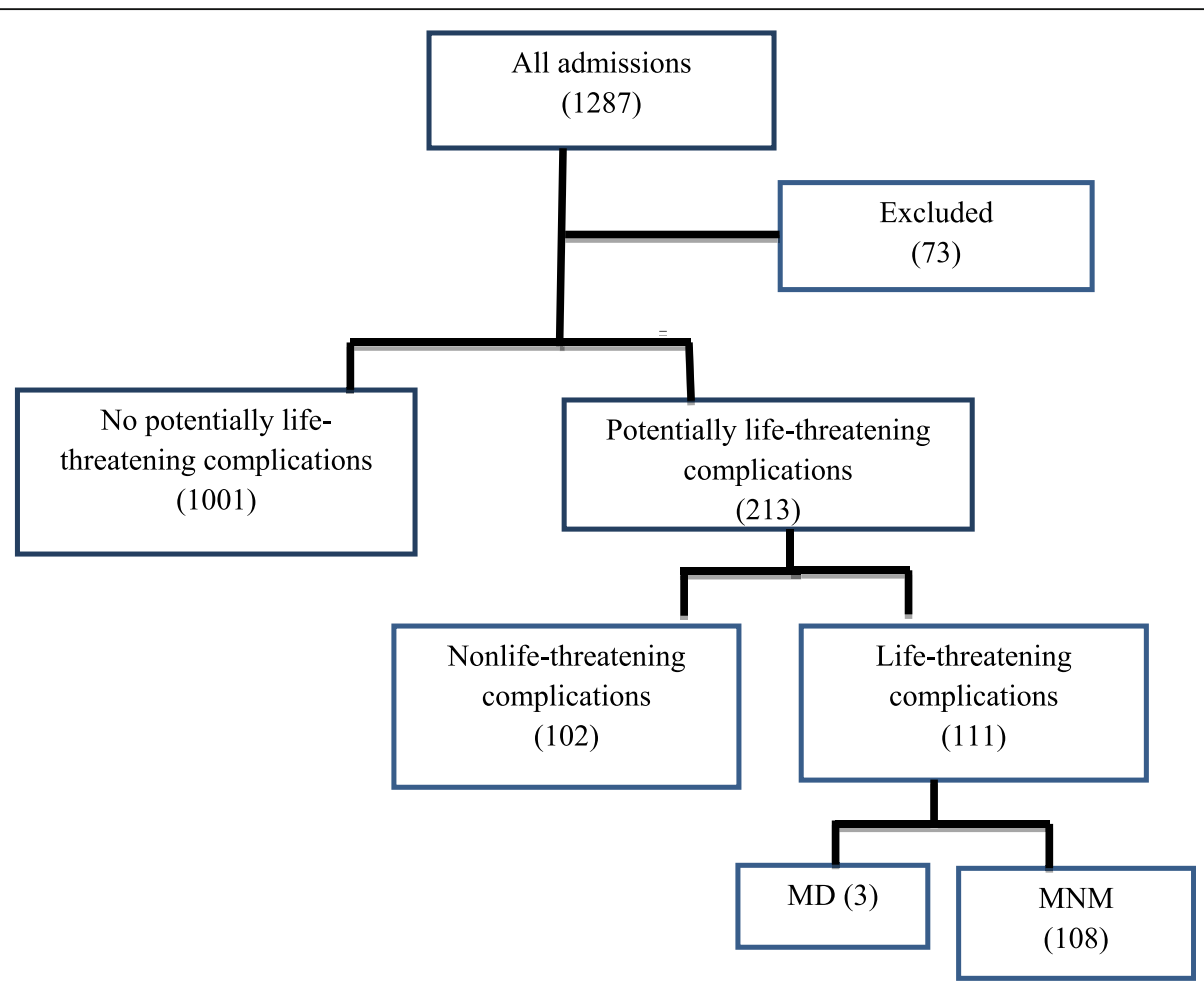

MNM, Maternal Near Miss; MD, Maternal Deaths

Fig. 1 Flow chart of maternal near miss in major private hospitals in eastern Ethiopia, 2020. MNM, Maternal Near Miss; MD, Maternal Deaths

Transfusion of $\geq 2$ units of blood (34.2\%), sepsis or systemic infection (23.4\%), and eclampsia (18\%) were the three most prevalent MNM events (Table 3). Obstetric hemorrhage $(54 ; 50 \%)$ and hypertensive disorders of pregnancy $(30 ; 27.8 \%)$ were the major underlying causes of MNM while anemia (44; 40.7\%) was the leading contributory cause of MNM (Table 4).

As shown in Table 5 coverage of key process indicators ranged from $69 \%$ for the use of oxytocin in severe postpartum hemorrhage to $80 \%$ for the use of magnesium sulphate in eclampsia. Mortality index was found to be highest among cases of uterine rupture (11.1\%) and least among cases of severe postpartum hemorrhage (7.7\%) (Table 5).

\section{Factors associated with MNM}

Age, ANC, history of previous cesarean section, chronic hypertension, and anemia in the index pregnancy were significantly associated with developing MNM (Table 6). Women $>35$ years old were 2.29 times more likely to develop MNM compared to those 20-34 years old. The odds of developing MNM among women with no ANC were 3 compared to women with at least one ANC. In addition, MNM was more likely among women with previous CS, who had chronic hypertension and anemic (Table 6).

\section{Discussion}

We found that the MNM ratio in major private hospitals in eastern Ethiopia was 92.1 per 1000 live births (95\% CI: 72-105). Majority of the MNM cases were already present on arrival or developed within $12 \mathrm{~h}$ of admission. MNM was more likely among women aged $\geq 35$ years, not have antenatal care, have history of cesarean section, anemic or have chronic hypertension.

Compared to previous studies which utilized the subSaharan Africa MNM tool, our finding is comparable with finding in Harar (80.2) [8], but higher than the study in public health facilities in Namibia (31.9) [13]. The variation might be due to differences in the study population or study settings (private vs. public). Compared to public facilities, where the Namibian study was conducted, women coming to private facilities are high risk population seeking specialized private care $[24,25]$. In addition, as only women from high income population or with known risk factors are seeking private facilities, there might be under estimation of live births (denominator of MNM) among low risk population which may use public facilities or lower facilities like health center in our study.

As expected, the MNM according to the WHO MNM criteria (40.9 per 1000 livebirths) resulted in under estimating MNM compared to the sub-Saharan Africa 
Table 1 Socio-demographic and obstetric characteristics of women in major private hospitals in Eastern Ethiopia, 2020 $(n=1214)$

\begin{tabular}{|c|c|c|c|}
\hline Variable & Category & Frequency & (\%) \\
\hline \multirow[t]{3}{*}{ Age in years } & $<20$ & 84 & 6.9 \\
\hline & $20-34$ & 1025 & 84.4 \\
\hline & $\geq 35$ & 105 & 8.7 \\
\hline \multirow[t]{2}{*}{ Residence } & Urban & 812 & 66.9 \\
\hline & Rural & 402 & 33.1 \\
\hline \multirow[t]{3}{*}{ Days of admission } & Working day & 862 & 71.0 \\
\hline & Weekends & 313 & 25.8 \\
\hline & Holidays & 39 & 3.2 \\
\hline \multirow[t]{2}{*}{ Referral status } & Self-referral & 1174 & 96.7 \\
\hline & $\begin{array}{l}\text { Referred from other } \\
\text { facility }\end{array}$ & 40 & 3.3 \\
\hline \multirow[t]{3}{*}{ Parity } & 0 & 233 & 19.2 \\
\hline & $1-2$ & 586 & 48.3 \\
\hline & 3 or more & 395 & 32.5 \\
\hline \multirow{2}{*}{$\begin{array}{l}\text { Received at least one } \\
\text { antenatal care }\end{array}$} & Yes & 1123 & 92.5 \\
\hline & No & 91 & 7.5 \\
\hline \multirow[t]{2}{*}{ History of still birth } & Yes & 85 & 7.0 \\
\hline & No & 1129 & 93.0 \\
\hline \multirow[t]{2}{*}{ History of abortion } & Yes & 244 & 20.1 \\
\hline & No & 970 & 79.9 \\
\hline \multirow[t]{2}{*}{ Previous cesarean section } & Yes & 167 & 13.8 \\
\hline & No & 1047 & 86.2 \\
\hline \multirow[t]{4}{*}{ Mode of delivery } & Vaginal delivery & 789 & 65.0 \\
\hline & $\begin{array}{l}\text { Emergency cesarean } \\
\text { section }\end{array}$ & 330 & 27.2 \\
\hline & $\begin{array}{l}\text { Elective cesarean } \\
\text { section }\end{array}$ & 85 & 7.0 \\
\hline & $\begin{array}{l}\text { Abortion or } \\
\text { laparotomy }\end{array}$ & 10 & 0.8 \\
\hline
\end{tabular}

MNM criteria (92.1 per 1000 live births). A similar under reporting of MNM in low resource settings by the WHO MNM criteria was previously reported [9-11]. The MNM ratio according to the WHO MNM criteria (40.9 per 1000 livebirths) is still higher compared to similar MNM studies in public health facilities in Ethiopia except a study by Woldeyes et al. [26] in Jimma, south western Ethiopia (50.4). A study conducted in two public facilities in the same location reported an MNM ratio of 17.2 per 1000 livebirths [8]. Our finding is, however, similar with MNM findings in Nigeria and Zanzibar, Tanzania $[27,28]$.

Our finding is much lower than the MNM ratio reported in a private tertiary hospital in Nigeria (262 per 1000 live births) [29] and the national estimates for Ethiopia (208 per 1000 live births) [20]. Given that majority of patients visiting a private tertiary maternity
Table 2 MNM indicators among women admitted in private hospitals in Eastern Ethiopia, 2020 [5]

\begin{tabular}{|c|c|c|}
\hline \multirow[t]{2}{*}{ Outcomes } & \multicolumn{2}{|c|}{$\begin{array}{l}\text { Near miss } \\
\text { indicators }\end{array}$} \\
\hline & SSA & $\begin{array}{l}\text { WHO } \\
{[5]}\end{array}$ \\
\hline $\begin{array}{l}\text { 1. All live births in the population under } \\
\text { surveillance }(n)\end{array}$ & 1173 & 1173 \\
\hline 2. Severe maternal outcomes (SMO) cases (n) & 111 & 51 \\
\hline Maternal near miss ( $\mathrm{n}$ ) & 108 & 48 \\
\hline Maternal death (n) & 3 & 3 \\
\hline \multicolumn{3}{|l|}{ 3. Overall near miss indicators } \\
\hline $\begin{array}{l}\text { Severe maternal outcome ratio } \\
\text { (per } 1000 \text { live births) }\end{array}$ & 94.6 & 43.5 \\
\hline Maternal near-miss ratio (per 1000 live births) & 92.1 & 40.9 \\
\hline Maternal near-miss mortality ratio (MNM:MD) & 36 & 16 \\
\hline Mortality index (\%) & 2.7 & 5.9 \\
\hline \multicolumn{3}{|l|}{ 4. Hospital access indicators } \\
\hline $\begin{array}{l}\text { SMO cases presenting the organ } \\
\text { dysfunction or maternal death within } 12 \mathrm{~h} \\
\text { of hospital stay (SMO12) (number) }\end{array}$ & 90 & 35 \\
\hline $\begin{array}{l}\text { Proportion of SMO12 cases among all SMO } \\
\text { cases }\end{array}$ & 81.1 & 68.6 \\
\hline $\begin{array}{l}\text { Proportion of } \mathrm{SMO} 12 \text { cases coming from } \\
\text { other health facilities }\end{array}$ & 21.1 & 14.3 \\
\hline SMO12 mortality index (\%) & 3.3 & 8.6 \\
\hline \multicolumn{3}{|l|}{ 5. Intra-hospital care } \\
\hline Intra-hospital SMO cases (number) & 21 & 13 \\
\hline Intra-hospital SMO rate (per 1000 live births) & 17.9 & 11.1 \\
\hline
\end{tabular}

SMO severe maternal outcome, MNM maternal near miss, MD maternal death, mortality index number of maternal deaths divided by all severe maternal outcomes (maternal near miss and maternal deaths)

hospital in the Nigerian study would be high-risk population compared to our general hospitals, this difference is expected. In addition, since the Ethiopian study included all women with any complication as a maternal near miss, this variation is also not unexpected [20].

In line with previous studies in Ethiopia and other low-resource settings, large number of women had MNM on arrival or developed within $12 \mathrm{~h}$ of admission $[17,26]$. This indicates marked delays in recognizing complications (delay one) or reaching the appropriate facilities (delay two) [5]. Given that majority of women were from urban areas and came to the facilities without referral, interventions to improve early recognition of complications are essential.

The MNM to mortality ratio of this study (36:1) is higher than findings from public hospitals in Harar (21:1 [8] and Jimma (5.8:1) [26]. This might reflect that women are receiving quality specialized care directly compared to the long chain of hierarchical care by different level of specialties before senior consultations in public facilities. This could also be characterized by 
Table 3 Distribution of MNM events in women with life threatening complications in private hospitals, Eastern Ethiopia, 2020

\begin{tabular}{|c|c|c|}
\hline Parameter & Frequency & $\begin{array}{l}\text { Percent } \\
(\%)\end{array}$ \\
\hline Maternal near miss(n) & 108 & \\
\hline Maternal death (n) & 3 & \\
\hline \multicolumn{3}{|l|}{ Clinical criteria } \\
\hline Cyanosis & 11 & 9.9 \\
\hline Gasping & 4 & 3.6 \\
\hline Respiratory rate $>40$ or $<6 / \mathrm{min}$ & 6 & 5.4 \\
\hline Shock & 19 & 17.1 \\
\hline Failure to form clots & 1 & 0.9 \\
\hline Loss of consciousness lasting $\geq 12 \mathrm{~h}$ & 2 & 1.8 \\
\hline Cardiac arrest & 1 & 0.9 \\
\hline Stroke & 1 & 0.9 \\
\hline Uncontrollable fit/total paralysis & 2 & 1.8 \\
\hline Jaundice in the presence of pre-eclampsia & 1 & 0.9 \\
\hline Eclampsia & 20 & 18.0 \\
\hline Uterine rupture & 9 & 8.1 \\
\hline Sepsis or severe systemic infection & 26 & 23.4 \\
\hline Pulmonary edema & 2 & 1.8 \\
\hline Severe abortion complications & 7 & 6.3 \\
\hline Severe pre-eclampsia with ICU admission & 12 & 10.8 \\
\hline Any clinical criteria & 88 & 79.3 \\
\hline \multicolumn{3}{|l|}{ Laboratory-based criteria } \\
\hline Oxygen saturation $<90 \%$ for $>60 \mathrm{~min}$ & 15 & 13.5 \\
\hline Creatinine $\geq 300 \mu \mathrm{mol} / \mathrm{l}$ or $\geq 3.5 \mathrm{mg} / \mathrm{dl}$ & 1 & 0.9 \\
\hline $\begin{array}{l}\text { Acute thrombocytopenia } \\
(<50,000 \text { platelets } / \mathrm{ml})\end{array}$ & 9 & 8.1 \\
\hline Loss of consciousness and ketoacids in urine & 4 & 3.6 \\
\hline Any Laboratory-based criteria & 27 & 24.3 \\
\hline \multicolumn{3}{|l|}{ Management based criteria } \\
\hline $\begin{array}{l}\text { Hysterectomy following infection or } \\
\text { hemorrhage }\end{array}$ & 9 & 8.1 \\
\hline Transfusion of $\geq 2$ units of red blood cells & 38 & 34.2 \\
\hline $\begin{array}{l}\text { Intubation and ventilation for } 60 \mathrm{~min} \text { not } \\
\text { related to anesthesia }\end{array}$ & 7 & 6.3 \\
\hline Cardio-pulmonary resuscitation & 6 & 5.4 \\
\hline Any Management based criteria & 51 & 45.9 \\
\hline Total severe maternal outcomes ${ }^{a}$ & 166 & \\
\hline
\end{tabular}

${ }^{a}$ Total exceeds total number of cases since some women have more than one inclusion criteria

referring out of critical patients to the nearby public referral hospitals, which might end up as 'death on arrival' elsewhere [30]. Although the World Health Organization recommends magnesium sulphate for all women with eclampsia [5], only $80 \%$ of cases with eclampsia received
Table 4 Underlying causes and contributing factors of lifethreatening complications among women in major private hospitals, Eastern Ethiopia, 2020

\begin{tabular}{lllll}
\hline & SMO & MNM & MD & MI \\
& n (\%) & n (\%) & n (\%) & \% \\
\hline Over all & 111 & 108 & 3 & 2.7
\end{tabular}

Underlying causes

$\begin{array}{cllll}\text { Obstetric hemorrhage } & \mathbf{5 5 ( 4 9 . 5 )} & \mathbf{5 4 ( 5 0 )} & \mathbf{1}(\mathbf{3 3 . 3}) & \mathbf{1 . 8} \\ \text { Abortion related } & 7(6.3) & 7(6.5) & 0(0) & 0.0 \\ \text { Ectopic pregnancy } & 4(3.6) & 4(3.7) & 0(0) & 0.0 \\ \text { Abruptio placenta } & 18(16.2) & 18(16.7) & 0(0) & 0.0 \\ \text { Placenta previa } & 7(6.3) & 7(6.5) & 0(0) & 0.0 \\ \text { Uterine rupture } & 9(8.1) & 8(7.4) & 1(33.3) & 11.1 \\ \quad \text { Severe postpartum } & 13(11.7) & 12(11.1) & 1(33.3) & 7.7 \\ \text { hemorrhage } & & & & \\ \text { Hypertensive disorders } & \mathbf{3 2 ( 2 8 . 8 )} & \mathbf{3 0 ( 2 7 . 8 )} & \mathbf{2 ( 6 6 . 7 )} & \mathbf{6 . 3} \\ \quad \text { Eclampsia } & 20(18.0) & 18(16.7) & 2(66.7) & 10 \\ \quad \text { Preeclampsia } & 12(10.8) & 12(11.1) & 0(0.0) & 0.0 \\ \text { Sepsis/severe systemic } & \mathbf{2 6 ( 2 3 . 4 )} & \mathbf{2 6 ( 2 4 . 1 )} & \mathbf{0 ( 0 . 0 )} & \mathbf{0 . 0} \\ \text { infection } & & & & \\ \text { Contributory causes } & & & & \\ \text { Anemia } & 46(41.4) & 44(40.7) & 2(66.7) & 4.3 \\ \text { Chronic hypertension } & 15(13.5) & 15(13.9) & 0(0.0) & 0.0 \\ \text { Heart disease } & 1(0.9) & 1(0.9) & 0(0.0) & 0.0\end{array}$

MNM maternal near miss, MD maternal death, $M I$ mortality index, SMO severe maternal outcome

magnesium sulphate. Similarly, only $69 \%$ of women with severe PPH received oxytocin. This should be assessed whether it was due to lack of supplies or poor documentation.

Consistent with findings from Australia [31], Brazil, and the United Kingdom [32, 33], MNM was more likely among older women ( $\geq 35$ years). Pregnancies in older women carries greater risk of hypertensive disorders of pregnancy, cesarean section or postpartum hemorrhage $[34,35]$ which are known risk factors for MNM. Women with no ANC were also more likely to develop MNM compared to women who had at least one. Similar association of no ANC and MNM has been previously reported in Ethiopia [36, 37], Brazil [38], and Nigeria [39]. This indicates the importance of ANC in identifying pregnancy complications and providing early treatment which gives the opportunity for early detections and treatments of complications thereby reducing near miss events.

Similar with previous findings in Ethiopia [14], Tanzania, and Brazil [38, 40], MNM was more likely among women who had history cesarean section. Women with prior cesarean section carry higher risk of uterine rupture, placenta previa or $\mathrm{PPH}$ in subsequent 
Table 5 Process and outcome indicators related with specific conditions among women with life-threatening complications in private hospitals of Eastern Ethiopia, 2020

\begin{tabular}{|c|c|c|}
\hline Indicator & Number & Percentage \\
\hline \multicolumn{3}{|l|}{ 1. Treatment of severe postpartum hemorrhage } \\
\hline Target population: women with severe PPH & 13 & \\
\hline Oxytocin & 9 & 69.2 \\
\hline Ergometrine & 8 & 61.5 \\
\hline Misoprostol & 10 & 76.9 \\
\hline Any uterotonics & 13 & \\
\hline Artery ligation (uterine/hypogastric & 1 & 7.7 \\
\hline Hysterectomy & 4 & 30.8 \\
\hline Mortality & 1 & 7.7 \\
\hline \multicolumn{3}{|l|}{ 2. Anticonvulsants for eclampsia } \\
\hline Target population: women with eclampsia & 20 & \\
\hline Magnesium sulfate & 16 & 80.0 \\
\hline Other anticonvulsants & 4 & 20.0 \\
\hline Any anticonvulsant & 20 & 100 \\
\hline Mortality & 2 & 10.0 \\
\hline \multicolumn{3}{|l|}{ 3. Treatment for sepsis } \\
\hline Target population: women with sepsis & 26 & \\
\hline Parenteral therapeutic antibiotics & 20 & 76.9 \\
\hline \multicolumn{3}{|l|}{ 4. Ruptured uterus } \\
\hline $\begin{array}{l}\text { Target population: women with ruptured } \\
\text { uterus }\end{array}$ & 9 & \\
\hline Hysterectomy & 7 & 77.8 \\
\hline Mortality & 1 & 11.1 \\
\hline
\end{tabular}

PPH postpartum hemorrhage

pregnancies [41]. In congruent with findings from studies in Ghana and Addis Ababa (Ethiopia), anemic women had higher risk of developing MNM [36, 42]. Nutritional intervention and iron supplementation for all women during pregnancy may help to prevent and improve anemia during pregnancy [43]. In addition, women with chronic hypertension were more likely to develop MNM than their counterparts, a finding previously reported in Ethiopia [36] and Nigeria [44]. This could be explained by the fact that chronic hypertension increases risk of severe pregnancy complications like super imposed preeclampsia and placental abruption thereby increasing odds of MNM [45].

We included all women admitted during pregnancy, childbirth or within 42 days of termination of pregnancy over 1 year and therefore not prone to sampling errors. However, we were unable to comment on the timeliness of treatments received and delays associated with management since the time between decision and actual treatments was rarely documented. In addition, majority of sociodemographic characteristics (income,
Table 6 Factors associated with MNM among women admitted in private hospitals in Eastern Ethiopia, $2020(n=1211)$

\begin{tabular}{|c|c|c|c|c|}
\hline \multirow[t]{2}{*}{ Variable } & \multicolumn{2}{|l|}{ MNM } & \multicolumn{2}{|c|}{ 95\% confidence interval } \\
\hline & $\begin{array}{l}\text { Yes } \\
(n=108)\end{array}$ & $\begin{array}{l}\text { No } \\
(n=1103)\end{array}$ & COR & $\mathrm{aOR}$ \\
\hline \multicolumn{5}{|c|}{ Age in years } \\
\hline $20-34$ & $74(7.2 \%)$ & $950(92.8 \%)$ & 1.0 & 1.0 \\
\hline$<20$ & $9(10.7 \%)$ & 75 (89.3\%) & $1.54(0.74-3.20)$ & $2.13(0.86-5.27)$ \\
\hline$\geq 35$ & $25(24.3 \%)$ & $78(75.7 \%)$ & $4.12(2.47-6.84)$ & $2.29(1.22-4.29)$ * \\
\hline \multicolumn{5}{|l|}{ Residence } \\
\hline Urban & $65(8 \%)$ & 745 (92\%) & 1.0 & 1.0 \\
\hline Rural & $43(10.7 \%$ & $358(89.3 \%)$ & $1.38(0.92-2.07)$ & $1.45(0.92-2.29)$ \\
\hline \multicolumn{5}{|c|}{ History of Stillbirth } \\
\hline No & $94(8.3)$ & $1033(91.7 \%)$ & 1.0 & 1.0 \\
\hline Yes & $14(16.7 \%)$ & $70(83.3 \%)$ & $2.20(1.19-4.05)$ & $1.84(0.93-3.64)$ \\
\hline \multicolumn{5}{|c|}{ History of Abortion } \\
\hline No & $77(8 \%)$ & 891 (92\%) & 1.0 & 1.0 \\
\hline Yes & $31(12.8 \%)$ & $212(87.2 \%)$ & $1.69(1.09-2.64)$ & $1.57(0.96-2.57)$ \\
\hline \multicolumn{5}{|c|}{ ANC utilization } \\
\hline Yes & $92(8.2 \%)$ & $1028(91.8)$ & 1.0 & 1.0 \\
\hline No & $16(17.6 \%)$ & 75 (82.4\%) & $2.38(1.33-4.26)$ & $3.04(1.58-5.83)^{* *}$ \\
\hline \multicolumn{5}{|l|}{ Parity } \\
\hline $1-2$ & $35(6.0 \%)$ & $551(94.0 \%)$ & 1.0 & 1.0 \\
\hline 0 & $18(7.8 \%)$ & $214(92.2 \%)$ & $1.32(0.73-2.39)$ & $1.76(0.85-3.64)$ \\
\hline$\geq 3$ & $55(14 \%)$ & $338(86 \%)$ & $2.66(1.71-4.13)$ & $1.58(0.94-2.67)$ \\
\hline \multicolumn{5}{|c|}{ Previous CS } \\
\hline No & $71(6.8 \%)$ & $974(93.2 \%)$ & 1.0 & 1.0 \\
\hline Yes & $37(22.3)$ & $129(77.7 \%)$ & $3.94(2.54-6.10)$ & $4.48(2.67-7.53)^{* * *}$ \\
\hline \multicolumn{5}{|c|}{ Chronic Hypertension } \\
\hline No & $94(8.2 \%)$ & $1048(91.8 \%)$ & 1.0 & 1.0 \\
\hline Yes & $14(20.3 \%)$ & $55(79.7 \%)$ & $2.84(1.52-5.29)$ & $3.13(1.57-6.26)^{* *}$ \\
\hline \multicolumn{5}{|c|}{ Anemia in current pregnancy } \\
\hline No & $66(6.3 \%)$ & $989(93.7 \%)$ & 1.0 & 1.0 \\
\hline Yes & $42(26.9 \%)$ & $114(73.1 \%)$ & $5.52(3.58-8.51)$ & $5.03(3.12-8.13){ }^{* * *}$ \\
\hline
\end{tabular}

MNM maternal near miss, ANC antenatal care, CS cesarean section, cOR crude odds ratio, $a O R$ adjusted odds ratio; ${ }^{*} p=0.010,{ }^{* *} p=0.001,{ }^{* * *} p=0.000$

educational status, partner's status, and occupation) which affect treatment seeking or outcomes were not assessed since they are not routinely documented in medical records. In addition, lack of studies in private hospitals in general and which utilized the adapted subSaharan African MNM criteria in particular, made comparing our findings with others to be difficult.

\section{Conclusion}

We found that the risk of MNM was significantly higher among women $\geq 35$ years, had no ANC, have history of CS, anemia in index pregnancy and chronic hypertension. Improving maternal and prenatal outcomes in private facilities should emphasize on women at risk of MNM: older, previous CS, anemic, no ANC, and chronic hypertension. Implementation of prenatal risk 
identification and prompt referral to the nearby hospitals are essential for reducing delays in provision of appropriate care. In addition, audit of appropriateness of treatments and delays in management of women in private hospitals is required if the goals for ending preventable maternal mortality is to be achieved.

\section{Abbreviations}

ANC: Antenatal Care; CS: Cesarean Section; ICU: Intensive Care Unit; MD: Maternal Death; MNM: Maternal Near Miss; PPH: Postpartum Hemorrhage; WHO: World Health Organization

\section{Acknowledgements}

We want to thank respective hospital managers for allowing us to conduct this study. We also want to thank Haramaya University for funding the study.

\section{Authors' contributions}

SGT and AKT conceived the study and wrote the original draft of the manuscript. Analysis and interpretation of data was done by SGT. AKT and NA supervised the proposal development, data collection, analysis and interpretation of data. AKT, NA and TM reviewed the draft manuscript for intellectual content and participated in the revision. AKT is the guarantor of the study. All authors approved the final version of the manuscript.

\section{Funding}

The study was funded by Haramaya University as part of MSC study to SGT.

\section{Availability of data and materials}

All data used for conclusion in this study are included in this article. Additional data are available from the corresponding author on reasonable request.

\section{Declarations}

\section{Ethics approval}

This study was approved by the institutional health research ethics review committee of College of Health and Medical Sciences, Haramaya University in Ethiopia (Ref no: IHRERC/045/2020). The study was conducted in accordance with regulations and guidelines for researches involving human beings. Since the study was retrospective, the need for informed consent was waived and permission was obtained from administrators of both hospitals. Confidentially of participants was maintained through use of anonymous data extraction.

\section{Consent for publication}

not applicable.

\section{Competing interests}

None.

\section{Author details}

${ }^{1}$ Department of midwifery, College of Medicine and Health Sciences, Wolkite University, Wolkite, Ethiopia. ${ }^{2}$ School of nursing and midwifery, College of Health and Medical Sciences, Haramaya University, P.O.B. 235, Harar, Ethiopia. ${ }^{3}$ Department of obstetrics and gynecology, University Medical Centre Groningen, University of Groningen, Groningen, the Netherlands.

Received: 10 November 2020 Accepted: 26 February 2021 Published online: 05 March 2021

\section{References}

1. GA UN. Transforming our world: the 2030 agenda for sustainable development. Division for Sustainable Development Goals. New York: World Health Organization; 2015.

2. World Health Organization: Trends in maternal mortality 2000 to 2017: estimates by WHO, UNICEF, UNFPA, World Bank Group and the United Nations Population Division. 2019

3. Creanga AA, Bateman BT, Kuklina EV, Callaghan WM. Racial and ethnic disparities in severe maternal morbidity: a multistate analysis, 2008-2010. Obstet Gynecol. 2014;210(5):435. e1-8.
4. Say L, Souza JP, Pattinson RC. Maternal near miss-towards a standard tool for monitoring quality of maternal health care. Best Pract Res Clin Obstetr Gynaecol. 2009;23(3):287-96.

5. World Health Organization: Evaluating the quality of care for severe pregnancy complications: the WHO near-miss approach for maternal health. 2011.

6. Pattinson RC, Buchmann E, Mantel G, Schoon M, Rees H. Can enquiries into severe acute maternal morbidity act as a surrogate for maternal death enquiries? BJOG. 2003;110(10):889-93.

7. Gebrehiwot Y, Tewolde BT. Improving maternity care in Ethiopia through facility based review of maternal deaths and near misses. Int J Gynecol Obstet. 2014:127:529-34.

8. Tura AK, Zwart J, van Roosmalen J, Stekelenburg J, van den Akker T, Scherjon S. Severe maternal outcomes in eastern Ethiopia: application of the adapted maternal near miss tool. Plos One. 2018;13(11):e0207350.

9. Nelissen E, Mduma E, Broerse J, Ersdal H, Evjen-Olsen B, van Roosmalen J, Stekelenburg J. Applicability of the WHO maternal near miss criteria in a low-resource setting. Plos One. 2013;8(4):e61248.

10. Tura AK, Trang TL, van den Akker T, van Roosmalen J, Scherjon S, Zwart J, Stekelenburg J. Applicability of the WHO maternal near miss tool in subSaharan Africa: a systematic review. BMC Pregnancy Childbirth. 2019;19(1):79-7.

11. van den Akker T, Beltman J, Leyten J, Mwagomba B, Meguid T, Stekelenburg J, van Roosmalen J. The WHO maternal near miss approach: consequences at Malawian District level. Plos One. 2013;8(1):e54805.

12. Tura AK, Stekelenburg J, Scherjon SA, Zwart J, van den Akker T, van Roosmalen J, Gordijn SJ. Adaptation of the WHO maternal near miss tool for use in sub-Saharan Africa: an International Delphi study. BMC Pregnancy Childbirth. 2017;17(1):445-x.

13. Heemelaar S, Kabongo L, Ithindi T, Luboya C, Munetsi F, Bauer A, Dammann A, Drewes A, Stekelenburg J, van den Akker T. Measuring maternal nearmiss in a middle-income country: assessing the use of WHO and subSaharan Africa maternal near-miss criteria in Namibia. Glob Health Action. 2019:12(1):1646036.

14. Kasahun AW, Wako WG. Predictors of maternal near miss among women admitted in Gurage zone hospitals, South Ethiopia, 2017: a case control study. BMC Pregnancy Childbirth. 2018;18(1):260-1.

15. Tessema GA, Laurence CO, Melaku YA, Misganaw A, Woldie SA, Hiruye A, Amare AT, Lakew Y, Zeleke BM, Deribew A. Trends and causes of maternal mortality in Ethiopia during 1990-2013: findings from the global burden of diseases study 2013. BMC Public Health. 2017;17(1):160.

16. Wakgar N, Dulla D, Daka D. Maternal near misses and death in southern Ethiopia: a retrospective study. Ethiopian J Reprod Health. 2019;11(2):9.

17. Liyew EF, Yalew AW, Afework MF, Essén B. Incidence and causes of maternal near-miss in selected hospitals of Addis Ababa, Ethiopia. Plos one. 2017:12(6):e0179013

18. Aman H, Negash S, Yusuf L. Cesarean delivery practices in teaching public and non-government/private MCH hospitals, Addis Ababa. Ethiop J Health Dev. 2014:28(1):22-8.

19. Tsega F, Mengistie B, Dessie $Y$, Mengesha M. Prevalence of cesarean section in urban health facilities and associated factors in eastern Ethiopia: hospital based cross sectional study. J Preg Child Health. 2015;2(3):169-73.

20. Geleto A, Chojenta C, Taddele T, Loxton D. Incidence of maternal near miss among women in labour admitted to hospitals in Ethiopia. Midwifery. 2019; 82:102597.

21. Harar General Hospital: Delivery registration 2019

22. Bilal Hospital: Delivery registration. 2019

23. World Health Organization: Beyond the numbers: reviewing maternal deaths and complications to make pregnancy safer. World Health Organization; 2004.

24. Phibbs CS, Mark DH, Luft HS, Peltzman-Rennie DJ, Garnick DW, Lichtenberg E, McPhee SJ. Choice of hospital for delivery: a comparison of high-risk and low-risk women. Health Serv Res. 1993;28(2):201.

25. Tebekaw Y, James Mashalla Y, Thupayagale-Tshweneagae G. Factors influencing Women's preferences for places to give birth in Addis Ababa, Ethiopia. Obstetr Gynecol Int. 2015:2015:439748.

26. Woldeyes WS, Asefa D, Muleta G. Incidence and determinants of severe maternal outcome in Jimma University teaching hospital, south-West Ethiopia: a prospective cross-sectional study. BMC Pregnancy Childbirth. 2018;18(1):255-x

27. Herklots T, Van Acht L, Meguid T, Franx A, Jacod B. Severe maternal morbidity in Zanzibar's referral hospital: measuring the impact of in-hospital care. Plos One. 2017;12(8):e0181470. 
28. Oladapo OT, Adetoro OO, Ekele BA, Chama C, Etuk SJ, Aboyeji AP, Onah HE, Abasiattai AM, Adamu AN, Adegbola $\mathrm{O}$. When getting there is not enough: a nationwide cross-sectional study of 998 maternal deaths and 1451 nearmisses in public tertiary hospitals in a low-income country. BJOG Int J Obstet Gynaecol. 2016;123(6):928-38.

29. Mbachu II, Ezeama C, Osuagwu K, Umeononihu OS, Obiannika C, Ezeama N. A cross sectional study of maternal near miss and mortality at a rural tertiary Centre in southern Nigeria. BMC pregnancy and Childbirth. 2017; 17(1):251.

30. Tura AK, Fage SG, Ibrahim AM, Mohamed A, Ahmed R, Gure T, Zwart J, van den Akker T. Beyond no blame: practical challenges of conducting maternal and perinatal death reviews in eastern Ethiopia. Global Health. 2020;8(2): 150-4.

31. Biro MA, Davey M, Carolan M, Kealy M. Advanced maternal age and obstetric morbidity for women giving birth in $\mathrm{V}$ ictoria, a ustralia: a population-based study. Aust N Z J Obstet Gynaecol. 2012;52(3):229-34.

32. Nair M, Kurinczuk JJ, Knight M. Ethnic variations in severe maternal morbidity in the UK-a case control study. Plos One. 2014;9(4):e95086.

33. Dias MAB, Domingues, Rosa Maria Soares Madeira, Schilithz AOC, NakamuraPereira M, Diniz CSG, Brum IR, martins AL, Filha MMT, Gama, Silvana Granado Nogueira da, Leal MdC: Incidence of maternal near miss in hospital childbirth and postpartum: data from the birth in Brazil study. Cadernos de saude publica 2014, 30:S169-S181.

34. Cleary-Goldman J, Malone FD, Vidaver J, Ball RH, Nyberg DA, Comstock CH, Saade GR, Eddleman KA, Klugman S, Dugoff L. Impact of maternal age on obstetric outcome. Obstet Gynecol. 2005:105(5):983-90.

35. Lamminpää R, Vehviläinen-Julkunen K, Gissler M, Heinonen S. Preeclampsia complicated by advanced maternal age: a registry-based study on primiparous women in Finland 1997-2008. BMC Pregnancy Childbirth. 2012; 12(1):47.

36. Liyew EF, Yalew AW, Afework MF, Essén B. Distant and proximate factors associated with maternal near-miss: a nested case-control study in selected public hospitals of Addis Ababa, Ethiopia. BMC Womens Health. 2018;18(1):28.

37. Worke MD, Enyew HD, Dagnew MM. Magnitude of maternal near misses and the role of delays in Ethiopia: a hospital based cross-sectional study. BMC Res Notes. 2019;12(1):585.

38. Domingues RMSM, MAB D, AOC S, do Carmo Leal M. Factors associated with maternal near miss in childbirth and the postpartum period: findings from the birth in Brazil National Survey, 2011-2012. Reprod Health. 2016; 13(3):115.

39. Adeoye IA, ljarotimi OO, Fatusi AO. What are the factors that interplay from normal pregnancy to near miss maternal morbidity in a Nigerian tertiary health care facility? Health Care Women Int. 2015;36(1):70-87.

40. Litorp H, Kidanto HL, Rööst M, Abeid M, Nyström L, Essén B. Maternal nearmiss and death and their association with caesarean section complications: a cross-sectional study at a university hospital and a regional hospital in Tanzania. BMC Pregnancy Childbirth. 2014;14(1):244.

41. Keag OE, Norman JE, Stock SJ. Long-term risks and benefits associated with cesarean delivery for mother, baby, and subsequent pregnancies: systematic review and meta-analysis. Plos Med. 2018;15(1):e1002494.

42. Peprah NY. Severe maternal morbidity and associated factors in Suntreso and Kumasi south government hospitals, Ashanti region. Ghana: University of Ghana; 2015

43. World Health Organization: WHO recommendations on antenatal care for a positive pregnancy experience. World Health Organization; 2016.

44. Adeoye IA, Onayade AA, Fatusi AO. Incidence, determinants and perinatal outcomes of near miss maternal morbidity in lle-lfe Nigeria: a prospective case control study. BMC Pregnancy Childbirth. 2013;13:93.

45. Seely EW, Ecker J. Chronic hypertension in pregnancy. Circulation. 2014; 129(11):1254-61.

\section{Publisher's Note}

Springer Nature remains neutral with regard to jurisdictional claims in published maps and institutional affiliations.

Ready to submit your research? Choose BMC and benefit from:

- fast, convenient online submission

- thorough peer review by experienced researchers in your field

- rapid publication on acceptance

- support for research data, including large and complex data types

- gold Open Access which fosters wider collaboration and increased citations

- maximum visibility for your research: over $100 \mathrm{M}$ website views per year

At BMC, research is always in progress.

Learn more biomedcentral.com/submissions 